\title{
Ten years of activities of the German Leprosy Relief Association in Senegal
}

\author{
C. NAUDIN \\ DAHW, Secretariat BP 8262, Dakar, Yoff, Senegal
}

\section{Introduction}

Senegal, a Sahelian country of $201,400 \mathrm{~km}^{2}$, situated at the northernmost point of West Africa at the Atlantic Ocean, has a population of 6,316,759 inhabitants, of which $46 \%$ are under 15 years old. The population is divided into six main ethnic groups, the homogeneity being essentially due to the Islamic religion $(90 \%$ of the population). The resources of the country are limited; mainly fishing, tourism and agriculture. The 10 administrative regions, divided into departments ( 3 per region) are connected by a good road network, which-because of satisfying climatic conditions-have good access throughout the year.

The equipment of the health infrastructure has improved in the last 10 years - in 1986 there were 16 hospitals and 579 health posts. However, there is still insufficient medical staff, which is concentrated on the urban centres - 159 doctors and 824 nurses.

The fight against leprosy is always done using a vertical system and in affiliation with the Service des Grandes Endemies (SGE). The administration of the Grandés Endemies (DGE) of the Ministry of Public Health (MSP) supervise one sector SGE per region, run by a doctor assisted by a group of 10-15 paramedical leprosy workers.

In Dakar the Institute for Applied Leprology (ILAD), with 4 doctors, 11 paramedical persons and 60 beds, is the centre of technical reference, research, training and hospitalization.

Since 1979 the German Leprosy Relief Association (GLRA) has been the ILEP coordinator in Senegal. Two proposals made by the GLRA to the Ministry of Health $(\mathrm{MoH})$ at the beginning have proved to be essential for the success of a programme. They are:

centralized and coordinated administration of the leprosy programme by the GLRA under the supervision of the Ministry of Health;

and a leading team reinforced by a doctor, an administrator and a person responsible for social matters, who already has had several years experience in Senegal. 


\title{
Evolution of the NLCP from 1980 to 1990
}

\author{
PLAN OF ACTION
}

There is no 'protocol for the National Leprosy Control Programme (NLCP), Senegal' which was founded and has developed in an informal, but logical way based on a plan of action of the GLRA team, supported by the paramedical leprosy workers of the SGE (with the consent and the supervision of the Ministry) and cooperating closely with the ILAD.

\section{FROM 1980 TO 1984}

The first 4 years were marked by the efforts made in reorganizing the SGE-retraining staff, the creation of laboratories (one per sector), adaptation of administration and logistics, data collection, etc.

\section{FROM 1985}

From 1985 onwards the different parts of a plan of action of a NLCP have been introduced step by step in the sectors, whereby the progress in each sector dependend on the dynamism of the leprosy staff concerned.

\section{MULTIDRUG THERAPY}

Multidrug therapy is one of the essential tasks of the NLCP and its implementation has only been possible, without risk, with the reorganization of the SGE. After a test in pilot areas in 1983 and in 1986 the project had a fast upturn from 1987, and within 3 years 10 out of 30 departments were covered by MDT. This corresponds to $20 \%$ of patients being under chemotherapy at the end of 1989.

\section{PREVENTION OF DISABILITIES}

After the training of hospital staff (disability grading, neuritis, etc.) a hospitalization room of 6 beds was opened by the SGE in each of the sector centres for treatment of grave neuritis and mutilation in 1987, accompanied by 21 Centers of Health Education for handicapped patients. At the same time the mobile footwear project of the ILAD (1983) spread all over the country under the supervision of the GLRA.

\section{HEALTH EDUCATION}

In spite of the urgency (leprosy was totally unknown in Senegal and case-finding had almost stopped) health education (HE) activities started a bit late in 1988 because it was necessary to reorganize the treatment centres.

Because teaching materials were elaborated upon on the spot (HE booklets, flipbooks, posters and slides) the information is based on three elements: the media, rural schools (about 42,000 schoolchildren were informed in 1988) and special targeting, i.e. doctors and teachers. 


\section{TRAINING}

Through the training of paramedical leprosy staff, which gradually became permanent and by profiting from data collection, fairly reliable statistics concerning the different sectors and tasks (laboratories, chemotherapy, mutilation, etc.) could be obtained in 1987. This made the permanent evaluation of strong and weak points of the NLCP possible and so the NLCP could consequently be adjusted.

\section{ADMINISTRATION AND PLANNING}

The rapid development of the NLCP has only been possible thanks to the speedy intensification of the administration by the GLRA (computerization, office organization, etc.), which was always tried to adjust its support to the acutal needs.

\section{SOCIAL PROGRAMME}

This progamme developed simultaneously, switching slowly from a socioeconomic stage (fishing, agriculture and workshops) for the 12 existing leprosy villages (973 patients, 4000 inhabitants) in 1980 to an extensive social reintegration programme in and outside of the leprosy villages (alphabetization projects, loan banks, school projects, etc.). This was realized thanks to the reinforcement of the social staff (employment of 13 persons from Senegal) by GLRA with the financial support of the German Government (BMZ).

\section{Evaluation of the NLCP}

Are the results corresponding to the efforts made? A short-term evaluation can only be made on certain aspects of the medical programme. Below are some statistics, but it must be realized that the NLCP only started on a large scale in 1985.

EVOLUTION OF SOME EPIDEMIOLOGICAL AND OPERATIONAL PARAMETERS

\section{Chart A}

\section{General facts}

Total number of registered patients

Total number of chemotherapy patients

Percentage of inactive patients released from chemotherapy

Treated persons registered by 31.12 .89 in \%o

Percentage of MB among the registered patients

Percentage of children among the registered patients

Percentage of mutilated patients (stage 2-3, WHO)

Percentage of insensitivity (stage 1 , WHO)

\begin{tabular}{cccc}
1981 & 1983 & 1985 & 1988 \\
\hline 16,143 & 14,218 & 12,216 & 11,625 \\
15,379 & 12,475 & 10,416 & 8,828 \\
$4 \cdot 8$ & $12 \cdot 2$ & $14 \cdot 7$ & 24 \\
$2 \cdot 95$ & $2 \cdot 40$ & $1 \cdot 65$ & $1 \cdot 40$ \\
$17 \cdot 3$ & $33 \cdot 9$ & $29 \cdot 4$ & $34 \cdot 5$ \\
$6 \cdot 3$ & $6 \cdot 7$ & $7 \cdot 4$ & $3 \cdot 6$ \\
& & & $18 \cdot 8$ \\
& & & 12
\end{tabular}




\section{Chart B}

\begin{tabular}{|c|c|c|c|c|}
\hline \multicolumn{5}{|l|}{ Case detection } \\
\hline Number of new cases (NC) & 1035 & 823 & 703 & 506 \\
\hline$\% \mathrm{NC}-\mathrm{MB}$ & 18.9 & $22 \cdot 3$ & $23 \cdot 3$ & $22 \cdot 3$ \\
\hline$\% \mathrm{NC}$ - children & $11 \cdot 6$ & $9 \cdot 5$ & $12 \cdot 8$ & $8 \cdot 3$ \\
\hline$\% \mathrm{NC}-$ mutilated persons $(2-3)$ & $14 \cdot 8$ & & & $15 \cdot 1$ \\
\hline
\end{tabular}

\section{STATISTICAL PARAMETERS OF MDT By 31 DECEMBER 1988}

Patients treated with MDT since 1983-2258 (of which 1032 were MB and 1226 PB); 1135 of which were under MDT at 31 December 1988. The regular attendance rate of MDT patients was more than $80 \%$.

Relapses: the few relapses found are in fact due to an error of classification prior to the introduction of MDT.

\section{COMMENTS}

In 8 years more than $40 \%$ of the patients were released from chemotherapy, the number of MDT patients rising rom 650 before 1986 to 2258 patients at the end of 1988 . The only important additional cost being the price of medication. Ninety-two per cent of the new cases in 1988 had a bacteriological examination, and the complications of secondary infection have almost disappeared where the 21 centres for health education have been opened. However, some weaknesses remain, only $34 \%$ of the patients have had their yearly control and case detection especially has declined considerably in 10 years, as the statistics (Chart B) indicate. Another relative failure is the case detection of neuritis (improved, because it was almost nonexistent in 1980, but still modest), which explains there being a percentage of mutilated persons similar to that of the rest of Africa.

\section{EFFICIENCY}

Due to a concerted financial effort and also to considerable man power, substantial progress has been made within these 10 years.

A posteriori, are the results justified?

Estimated cost for a chemotherapy patient, 21,000 CFA (apart from ILAD costs).

Estimated social cost per patient, 6692 CFA.

Number of patients per doctor SGE, 900 patients.

Number of patients per nurse SGE, 200 patients.

The cost seems to be high, but the results are tangible and this should be the price for winning the fight and for providing all Senegal with MDT till 1994. This would reduce the number of chemotherapy patients to about 1500 persons at that time. 


\section{Conclusion}

Before 1979 the leprosy programme was confined to distributing Disulone regularly and to the treatment of mutilations due to secondary infections.

In 1980 the emergence of a structured programme working on all the sociomedical problems caused by the disease has considerably changed the strategy.

The human factor contributed, in a decisive way, to the relative success of the undertaking, the paramedical staff of the SGE, the driving force of the programme, found the basically necessary motivation, which together with an up-grading of its activities (acceptance of responsibility) led to a better working atmosphere (efficient administration).

The potential result will be the disappearance of leprosy as an endemic disease by 1995 in Senegal, which would offer the possibility of integrating totally and without risk the leprosy service into the general health service. This is the desire of WHO, but this is also proof of the success of the NLCP. Integration has already been implemented in certain areas under MDT for more than 2 years.

As a consequence the GLRA, in its role as technical consultant for the creation and planning of the NLCP, modulates its financial and logistic support towards the Ministry and contributes considerably to the results obtained. 